\title{
Application of Nondestructive Radio Tracer Technique in Performance Evaluation of Anion Exchange Resins Duolite ARA-9366 and Duolite A-171
}

\author{
P. U. Singare \\ Department of Chemistry, Bhavan's College, Munshi Nagar, Andheri (West), Mumbai 400 058, India \\ Tel No. + 9122 26256451/ 52; Fax No. + 912226256453 \\ *E-mail address: pravinsingare@gmail.com
}

\begin{abstract}
Radio analytical technique as a non-destructive technique was used in the present investigation to trace the kinetics of ion-isotopic exchange reaction taking place in Duolite ARA-9366 (nuclear grade) and Duolite A-171 (non-nuclear grade) anion exchange resins. The kinetics data suggest that during iodide ion-isotopic exchange reactions under identical experimental conditions of $40.0^{\circ} \mathrm{C}, 1.000$ $\mathrm{g}$ of ion exchange resins and $0.003 \mathrm{M}$ labeled iodide ion solution, the values of specific reaction rate $\left(\mathrm{min}^{-1}\right)$, amount of iodide ion exchanged $(\mathrm{mmol})$, initial rate of iodide ion exchange $(\mathrm{mmol} / \mathrm{min})$ and $\log \mathrm{K}_{\mathrm{d}}$ were $0.176,0.383,0.067$ and 7.8 respectively for Duolite ARA-9366 resin, which was higher than $0.142,0.353,0.050$ and 7.0 respectively as that obtained for Duolite A-171 resins. Also it is observed that at a constant temperature of $40.0^{\circ} \mathrm{C}$, as the concentration of labeled iodide ion solution increases $0.001 \mathrm{M}$ to $0.004 \mathrm{M}$, the percentage of iodide ions exchanged increases from $49.20 \%$ to $51.80 \%$ for Duolite ARA-9366 resins; and from $45.20 \%$ to $47.80 \%$ for Duolite A-171 resins. The similar trend was observed for the two resins during bromide ion-isotopic exchange reactions. The overall results indicate superior performance of Duolite ARA-9366 resins over Duolite A-171 resins under identical operational parameters.
\end{abstract}

Key words: non-destructive tracer technique; radio analytical technique; radioactive tracer isotopes; ${ }^{131} \mathrm{I}$; ${ }^{82} \mathrm{Br}$; reaction kinetics; ion-isotopic exchange reactions; nuclear grade resin; Duolite ARA-9366; Duolite A-171

\section{INTRODUCTION}

The increasing importance of organic ion exchangers in nuclear power plant operations and in the fuel reprocessing sector for the treatment of liquid radioactive waste is recognized globally. The ion exchange resins are not only used in removal of radionuclide in liquid radioactive waste but also in rare earth elements separation and water purification. The use of highly specific nuclear grade resins is most common in the nuclear industries [1-5]. The high capacity, wide applicability, wide versatility and low cost relative of synthetic organic ion exchange resins make them superior over some synthetic inorganic media. In spite of extensive work done in development of new organic ion exchange resins so as to match the requirements in industries, different aspects of ion exchange technologies are still studied 
continuously so as to improve the performance of those resins in various technical applications [6-11]. When designing an ion exchange processing system it is desirable to have an appreciation of the rate at which the reaction will occur. The required contact time will influence the physical size of the plant. When an ion exchanger particle is brought in contact with a solution there is a static liquid film formed around it, the thickness of which may vary between 10 and $100 \mathrm{~mm}$, depending on the rate of flow of liquid past the particle. The ion exchange reaction occurring between the resin particle and the solution will involve diffusion of the ions through the bulk solution in order to reach the ion exchanger particle, diffusion of the ion through the hydrated film surrounding the particle, diffusion of the ion across the film-particle interface, diffusion of the ion through the particle and finally the actual chemical reaction involving the exchange of ions. This is a simplified picture of the mechanism of an ion exchange process and its kinetics. The kinetics of ion exchange reaction may be affected by a number of parameters, such as the nature of the exchanger, the nature of the counter ions, the extent of agitation, the concentration of the counter ions, etc.

The actual rates of ion exchange can vary over a wide range, requiring a few seconds to several months to reach equilibrium. For a particular liquid-ion exchanger combination, the distribution coefficient $(K d)$ can be measured for each radionuclide and/or species present in the solution. The distribution coefficient can be used directly to calculate the amount of ion exchange medium that is needed to achieve a desired decontamination for a certain amount of liquid in a batch process. Under dynamic conditions, in which the ion exchange medium is used in a packed bed or in a column, the distribution coefficient can be used to calculate the theoretical maximum capacity of the ion exchange bed. Although there are many alternative methods available for measurement of distribution coefficient $(K d)$ values and to study the kinetics of ion exchange reactions, radioactive tracer isotope is one of the sensitive analytical techniques. By monitoring the radioactivity continuously, the migration of the tracer and in turn, of the bulk matter under investigation, can be followed. As a result radioisotopes have become useful tool and almost every branch of industry which uses them [12] and radiotracer methodology is described extensively in the literature [13-15]. Considering the extensive technological application of radioactive tracers, in the present investigation, attempts are made to apply the same technique to study the kinetics of ion-isotopic exchange reactions in Duolite ARA-9366 (nuclear grade) and Duolite A-171 (non-nuclear grade) anion exchange resins. The kinetics data so obtained was further used for characterization of the two resins.

\section{EXPERIMENTAL}

\section{1. Conditioning of ion exchange resins}

Duolite ARA-9366 is a nuclear grade resin in hydroxide form and Duolite A-171 is a non-nuclear grade resin in chloride form (both supplied by Auchtel Product Ltd., Mumbai, India). Both are strongly basic anion exchange resins having quaternary ammonium $\mathrm{N}^{+}\left(\mathrm{CH}_{3}\right)_{3}$ functional group. Details regarding the properties of the resins used are given in Table 1. These resins were converted separately in to iodide / bromide form by treatment with $10 \% \mathrm{KI} / \mathrm{KBr}$ solution in a conditioning column which is adjusted at the flow rate as $1 \mathrm{~mL} /$ min. The resins were then washed with double distilled water, until the washings were free from iodide/bromide ions as tested by $\mathrm{AgNO}_{3}$ solution. These resins in bromide and iodide form were then dried separately over $\mathrm{P}_{2} \mathrm{O}_{5}$ in desiccators at room temperature. 
Table 1. Properties of ion exchange resins.

\begin{tabular}{|c|c|c|c|c|c|}
\hline $\begin{array}{c}\text { Ion } \\
\text { exchange } \\
\text { resin }\end{array}$ & Matrix & $\begin{array}{c}\text { Moisture } \\
\text { content } \\
(\%)\end{array}$ & $\begin{array}{c}\text { Operating } \\
\mathrm{pH}\end{array}$ & $\begin{array}{c}\text { Maximum } \\
\text { operating } \\
\text { temperature } \\
\left({ }^{\circ} \mathrm{C}\right)\end{array}$ & $\begin{array}{c}\text { Total } \\
\text { exchange } \\
\text { capacity } \\
(\mathrm{meq} . / \mathrm{mL})\end{array}$ \\
\hline $\begin{array}{c}\text { Duolite } \\
\text { ARA-9366 }\end{array}$ & $\begin{array}{c}\text { Polystyrene } \\
\text { copolymer }\end{array}$ & 60 & $0-14$ & 60 & 1.00 \\
\hline $\begin{array}{c}\text { Duolite } \\
\text { A-171 }\end{array}$ & $\begin{array}{c}\text { Polystyrene } \\
\text { copolymer }\end{array}$ & 55 & $0-14$ & 100 & 0.80 \\
\hline
\end{tabular}

\section{2. Radioactive Tracer Isotopes}

2.

Details regarding the isotopes used in the present experimental work are given in Table

Table 2. Properties of ${ }^{131} \mathrm{I}$ and ${ }^{82} \mathrm{Br}$ tracer isotopes [12].

\begin{tabular}{|c|c|c|c|c|c|}
\hline Isotopes & Half-life & $\begin{array}{c}\text { Radioactivity } \\
/ \mathrm{mCi}\end{array}$ & $\begin{array}{c}\gamma \text { - energy } \\
/ \mathrm{MeV}\end{array}$ & $\begin{array}{c}\text { Chemical } \\
\text { form }\end{array}$ & $\begin{array}{c}\text { Physical } \\
\text { form }\end{array}$ \\
\hline $131 \mathrm{I}$ & $8.04 \mathrm{~d}$ & 5 & 0.36 & Iodide* & Aqueous \\
\hline $82 \mathrm{Br}$ & $36 \mathrm{~h}$ & 5 & 0.55 & Bromide** $^{*}$ & Aqueous \\
\hline
\end{tabular}

* Sodium iodide in dilute sodium sulphite.

** Ammonium bromide in dilute ammonium hydroxide.

\section{3. Study on kinetics of iodide ion-isotopic exchange reaction}

In a stoppered bottle $250 \mathrm{~mL}(V)$ of $0.001 \mathrm{M}$ iodide ion solution was labeled with diluted ${ }^{131}$ I radioactive solution using a micro syringe, such that $1.0 \mathrm{~mL}$ of labeled solution has a radioactivity of around 15,000 cpm (counts per minute) when measured with $\gamma$-ray spectrometer having NaI (Tl) scintillation detector. Since only about 50-100 $\mu \mathrm{L}$ of the radioactive iodide ion solution was required for labeling the solution, its concentration will remain unchanged, which was further confirmed by potentiometer titration against $\mathrm{AgNO}_{3}$ solution. The above labeled solution of known initial activity $\left(A_{i}\right)$ was kept in a thermostat adjusted to $30.0^{\circ} \mathrm{C}$. The swelled and conditioned dry ion exchange resins in iodide form weighing exactly $1.000 \mathrm{~g}(\mathrm{~m})$ were transferred quickly into this labeled solution which was vigorously stirred by using mechanical stirrer and the activity in cpm of $1.0 \mathrm{~mL}$ of solution was measured. The solution was transferred back to the same bottle containing labeled solution after measuring activity. The iodide ion-isotopic exchange reaction can be represented as:

$$
\mathrm{R}-\mathrm{I}+\mathrm{I}^{*^{-}} \text {(aq.) } \rightleftharpoons \mathrm{R}-\mathrm{I}^{*}+\mathrm{I}^{-}{ }_{(\text {aq. })}
$$

here R-I represents ion exchange resin in iodide form; $\mathrm{I}^{*^{-}}{ }_{\text {(aq.) }}$ represents aqueous iodide ion solution labeled with ${ }^{131}$ I radiotracer isotope [25-27]. The activity of solution was measured at a fixed interval of every $2.0 \mathrm{~min}$. The final activity $\left(A_{f}\right)$ of the solution was also measured after $3 \mathrm{~h}$ which was sufficient time to attain the equilibrium [16-20,25,26]. The activity 
measured at various time intervals was corrected for background counts. Similar experiments were carried out by equilibrating separately $1.000 \mathrm{~g}$ of ion exchange resin in iodide form with labeled iodide ion solution of four different concentrations ranging up to $0.004 \mathrm{M}$ at a constant temperature of $30.0{ }^{\circ} \mathrm{C}$. The same experimental sets were repeated for higher temperatures up to $45.0{ }^{\circ} \mathrm{C}$.

\section{4. Study on kinetics of bromide ion-isotopic exchange reaction}

The experiment was also performed to study the kinetics of bromide ion- isotopic exchange reaction by equilibrating $1.000 \mathrm{~g}$ of ion exchange resin in bromide form with labeled bromide ion solution in the same concentration and temperature range as above. The labeling of bromide ion solution was done by using ${ }^{82} \mathrm{Br}$ as a radioactive tracer isotope for which the same procedure as explained above was followed. The bromide ion-isotopic exchange reaction can be represented as:

$$
\mathrm{R}-\mathrm{Br}+\mathrm{Br}^{*-} \text { (aq.) } \rightleftharpoons \mathrm{R}-\mathrm{Br}^{*}+\mathrm{Br}^{-} \text {(aq.) }
$$

here $\mathrm{R}-\mathrm{Br}$ represents ion exchange resin in bromide form; $\mathrm{Br}^{*^{-}}{ }_{\text {(aq.) }}$ represents aqueous bromide ion solution labeled with ${ }^{82} \mathrm{Br}$ radiotracer isotope [25-27].

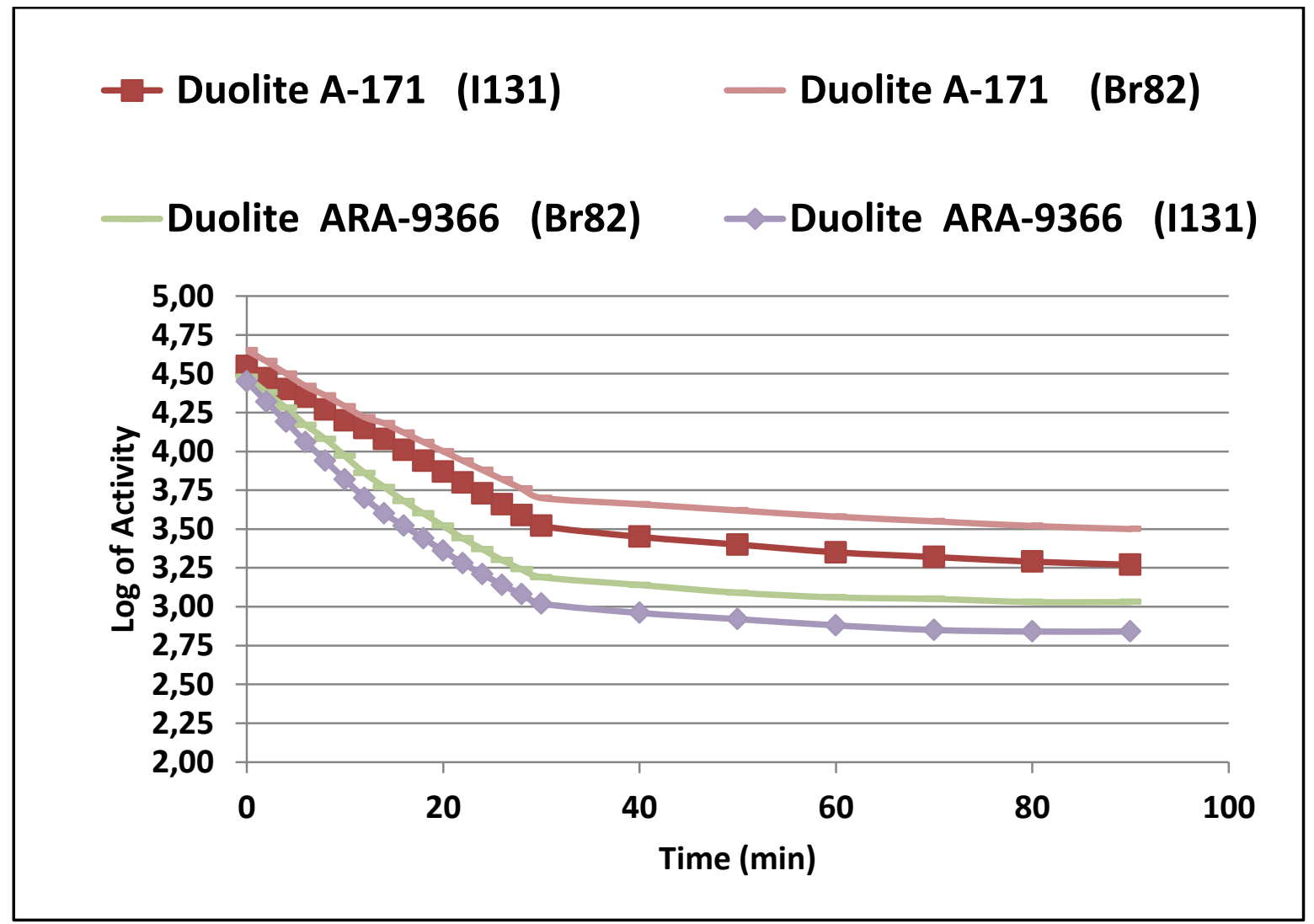

Figure 1. Kinetics of Ion-Isotopic Exchange Reactions.

Amount of ion exchange resin $=1.000 \mathrm{~g}$, Concentration of labeled exchangeable ionic solution $=0.003 \mathrm{M}$, Volume of labeled ionic solution $=250 \mathrm{~mL}$, Temperature $=40.0^{\circ} \mathrm{C}$. 
Table 3. Concentration effect on Ion-Isotopic Exchange Reactions.

Amount of ion exchange resin $=1.000 \mathrm{~g}$

Volume of labeled ionic solution $=250 \mathrm{~mL}$

Temperature $=40.0^{\circ} \mathrm{C}$

\begin{tabular}{|c|c|c|c|c|c|c|}
\hline$\stackrel{\circ}{8}$ & 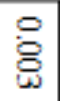 & $\stackrel{ᄋ}{8}$ & $\stackrel{\varrho}{\varrho}$ & \multicolumn{3}{|c|}{$\begin{array}{l}\text { Concentration of ionic solution } \\
\text { (M) }\end{array}$} \\
\hline $\bar{\S}$ & 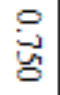 & $\stackrel{\circ}{\mathscr{B}}$ & $\stackrel{\circ}{\mathrm{N}}$ & \multicolumn{3}{|c|}{$\begin{array}{l}\text { Amount of ions in } 250 \mathrm{~mL} \text { solution } \\
\qquad(\mathrm{mmol})\end{array}$} \\
\hline$\stackrel{\circ}{\infty}$ & $\stackrel{\circ}{\rightleftarrows}$ & $\stackrel{\circ}{\frac{8}{1}}$ & $\stackrel{\circ}{u_{n}}$ & $\begin{array}{c}\text { Specific reaction rate of } \\
\text { rapid process } \\
\text { min }^{-1}\end{array}$ & \multirow{4}{*}{ 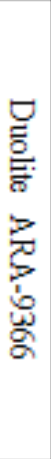 } & \multirow{8}{*}{ 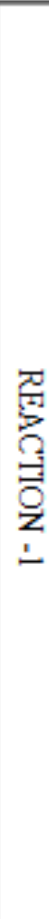 } \\
\hline$\underset{\infty}{\stackrel{\odot}{\omega}}$ & 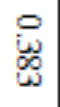 & $\stackrel{O}{\omega}$ & $\stackrel{\circ}{\omega}$ & $\begin{array}{l}\text { Amount of iodide ion } \\
\text { exchanged (mmol) }\end{array}$ & & \\
\hline$\stackrel{\odot}{9}$ & $\stackrel{\odot}{\mathscr{g}}$ & $\stackrel{\circ}{\rightleftarrows}$ & $\stackrel{\varrho}{6}$ & $\begin{array}{l}\text { Initial rate of iodide ion } \\
\text { exchange (mmol/min) }\end{array}$ & & \\
\hline$\infty$ & $\vec{\infty}$ & $\overrightarrow{\mathrm{N}}$ & 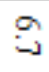 & $\log \mathrm{K}_{d}$ & & \\
\hline 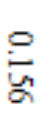 & $\stackrel{\ominus}{\mathrm{E}}$ & $\stackrel{\varrho}{\omega}$ & $\stackrel{\varrho}{\omega_{n}}$ & $\begin{array}{c}\text { Specific reaction rate of } \\
\text { rapid process } \\
\text { min }^{-1}\end{array}$ & \multirow{4}{*}{ 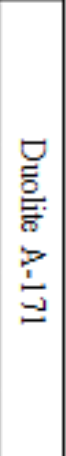 } & \\
\hline 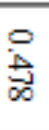 & $\stackrel{0}{\omega}$ & $\stackrel{0}{\mathcal{H}^{\prime}}$ & $\stackrel{\varrho}{\omega}$ & $\begin{array}{l}\text { Amount of iodide ion } \\
\text { exchanged } \\
\text { (mmol) }\end{array}$ & & \\
\hline$\stackrel{\varrho}{\stackrel{\varrho}{\Xi}}$ & $\stackrel{\circ}{\stackrel{\circ}{g}}$ & $\stackrel{\circ}{\mathscr{S}}$ & $\stackrel{\varrho}{\varrho}$ & $\begin{array}{l}\text { Initial rate of iodide ion } \\
\text { exchanged ( } \mathrm{mmol} / \mathrm{min})\end{array}$ & & \\
\hline$\vec{u}$ & $\vec{b}$ & or & $\stackrel{\circ}{0}$ & $\log K_{s}$ & & \\
\hline$\stackrel{\circ}{8}$ & $\stackrel{\ominus}{\oplus}$ & $\stackrel{\circ}{\varrho}$ & $\stackrel{\circ}{\infty}$ & $\begin{array}{c}\text { Specific reaction rate of } \\
\text { rapid process } \\
\text { min }^{-1}\end{array}$ & \multirow{4}{*}{ 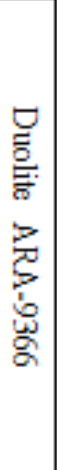 } & \multirow{8}{*}{ 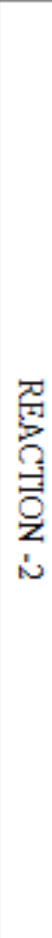 } \\
\hline 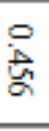 & $\stackrel{0}{\omega}$ & $\stackrel{0}{\underline{\omega}}$ & $\stackrel{0}{8}$ & $\begin{array}{l}\text { Amount of bromide ion } \\
\text { exchanged } \\
\text { (mmol) }\end{array}$ & & \\
\hline$\stackrel{\circ}{\stackrel{\circ}{g}}$ & $\stackrel{\circ}{\circ}$ & $\stackrel{\circ}{8}$ & $\stackrel{\varrho}{\varrho}$ & $\begin{array}{l}\text { Initial rate of bromide ion } \\
\text { exchange ( } \mathrm{mmol} / \mathrm{min})\end{array}$ & & \\
\hline 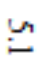 & $\vec{\alpha}$ & $\mathbb{b}$ & س山 & $\log \mathrm{K}_{d}$ & & \\
\hline$\stackrel{0}{\underbrace{}_{-j}}$ & $\stackrel{\varrho}{\infty}$ & $\stackrel{0}{\Xi}$ & $\stackrel{\circ}{8}$ & $\begin{array}{l}\text { Specific reaction rate of } \\
\text { rapid process } \\
\text { min }^{-1}\end{array}$ & \multirow{4}{*}{ 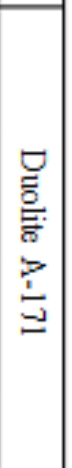 } & \\
\hline $\begin{array}{l}\stackrel{0}{\oplus} \\
\frac{\pi}{2}\end{array}$ & $\stackrel{0}{8}$ & $\stackrel{\circ}{6}$ & $\stackrel{\circ}{8}$ & $\begin{array}{l}\text { Amount of bromide ion } \\
\text { exchanged } \\
\text { (mmol) }\end{array}$ & & \\
\hline$\stackrel{\circ}{\stackrel{\circ}{\leftrightarrow}}$ & $\stackrel{\circ}{\stackrel{心}{心}}$ & $\stackrel{\circ}{\stackrel{8}{3}}$ & $\stackrel{\circ}{8}$ & $\begin{array}{l}\text { Initial rate of bromide ion } \\
\text { exchange ( } \mathrm{mmol} / \mathrm{min})\end{array}$ & & \\
\hline $\overrightarrow{i \omega}$ & $\omega$ & $\underset{\Delta}{\omega}$ & $\ddot{\omega}$ & $\log K_{\phi}$ & & \\
\hline
\end{tabular}


Table 4. Temperature effect on Ion-Isotopic Exchange Reactions. Amount of ion exchange resin $=1.000 \mathrm{~g}$

Concentration of labeled exchangeable ionic solution $=0.003 \mathrm{M}$

Volume of labeled ionic solution $=250 \mathrm{~mL}$

Amount of exchangeable ions in $250 \mathrm{~mL}$ labeled solution $=0.750 \mathrm{mmol}$

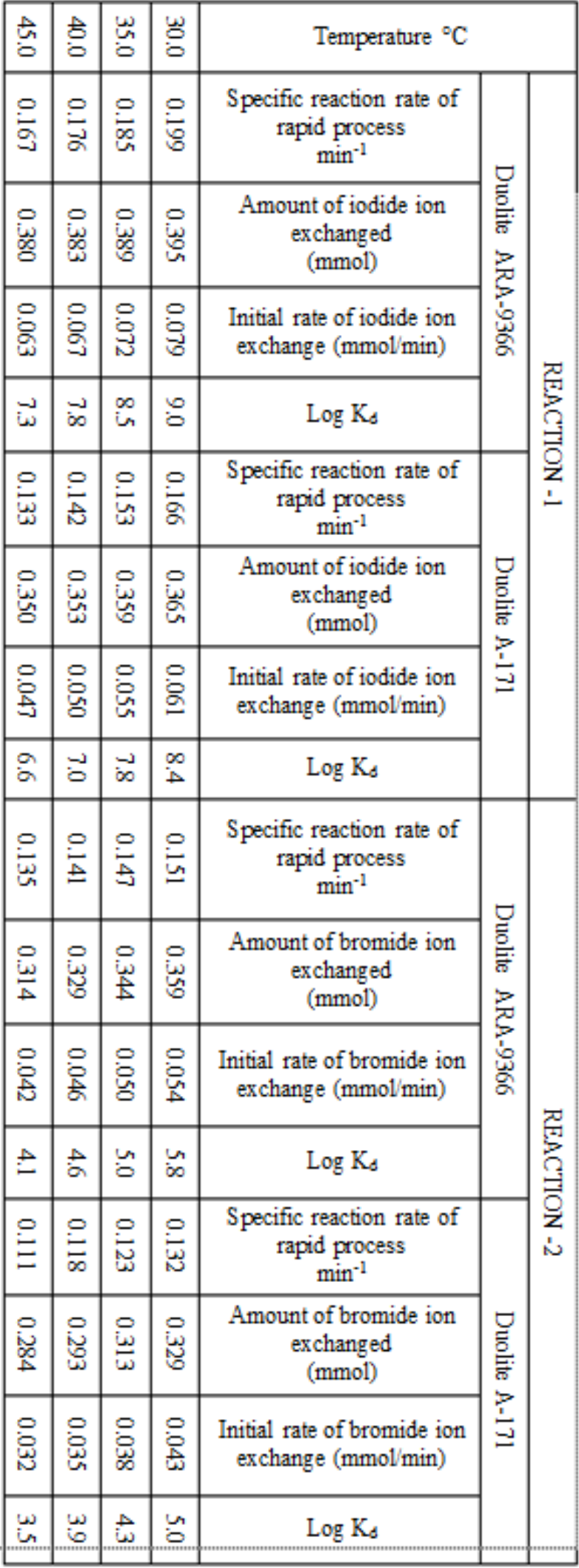




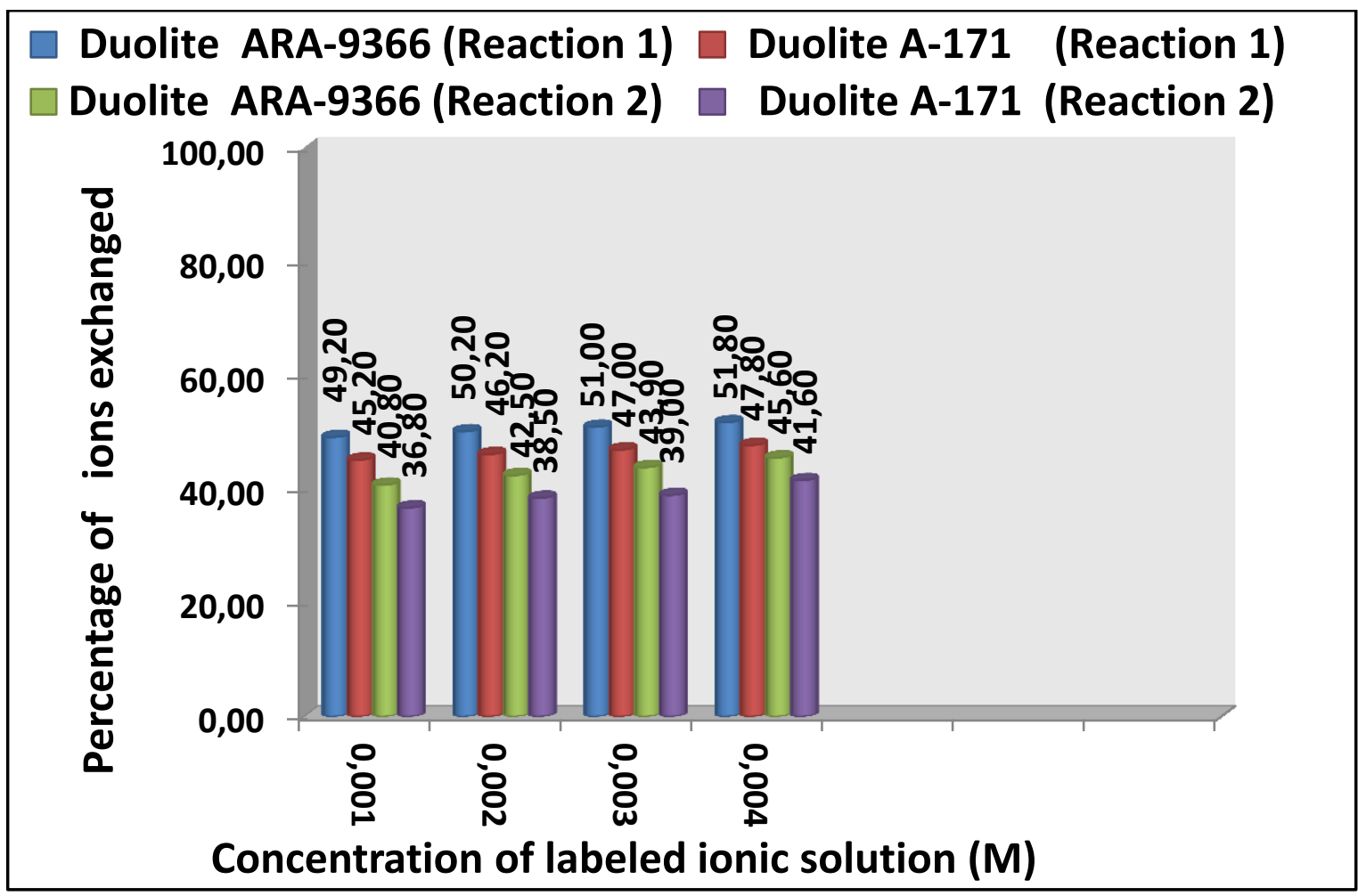

Figure 2. Variation in Percentage Ions Exchanged with Concentration of Labeled Ionic Solution. Amount of ion exchange resin $=1.000 \mathrm{~g}$, Volume of labeled ionic solution $=250 \mathrm{~mL}$, Temperature $=40.0^{\circ} \mathrm{C}$

\section{Duolite ARA-9366 (Reaction 1) $\square$ Duolite A-171 (Reaction 1) Duolite ARA-9366 (Reaction 2) $\square$ Duolite A-171 (Reaction 2)}

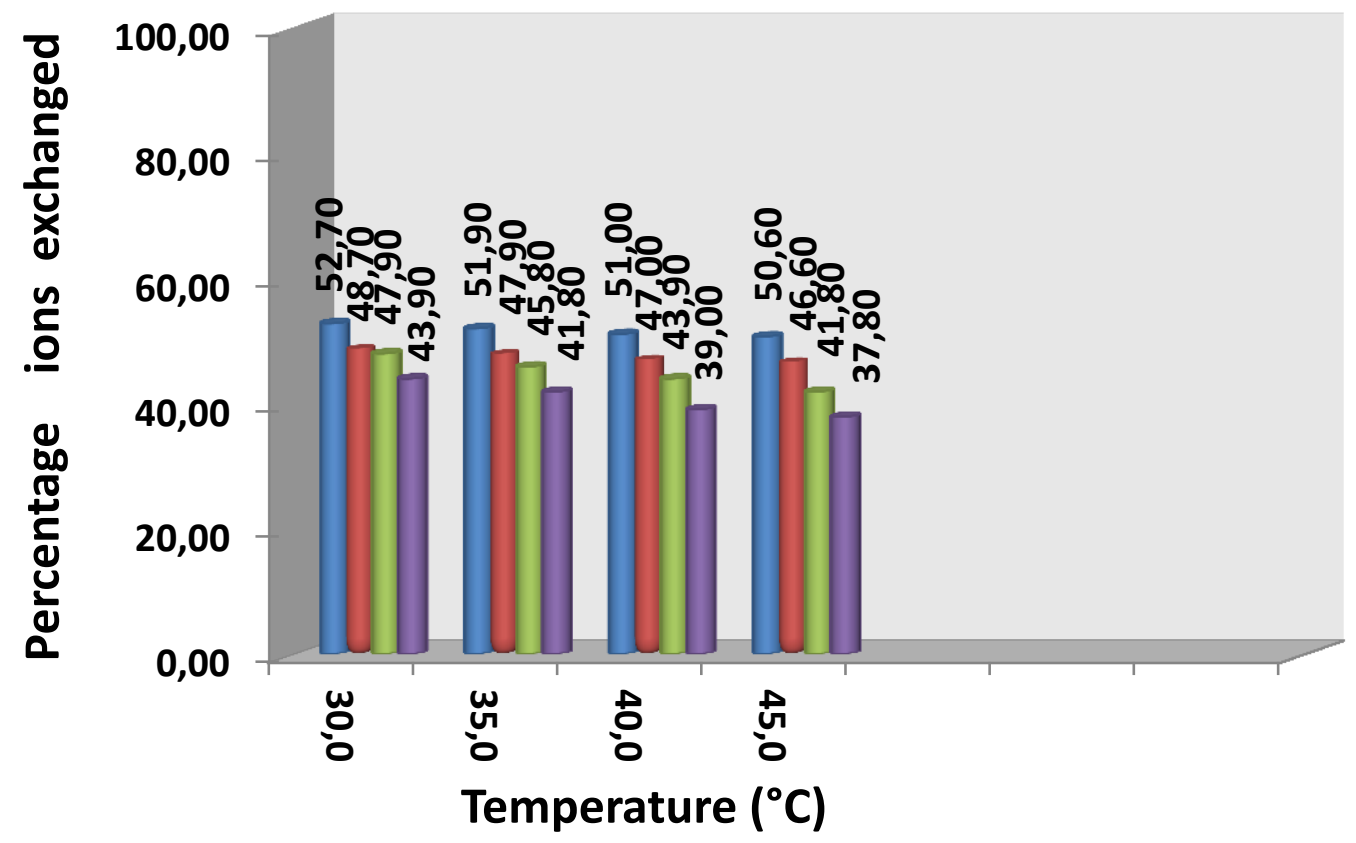

Figure 3. Variation in Percentage Ions Exchanged with Temperature of Labeled Ionic Solution. Amount of ion exchange resin $=1.000 \mathrm{~g}$, Concentration of labeled exchangeable ionic solution $=0.003 \mathrm{M}$, Volume of labeled ionic solution $=250 \mathrm{~mL}$, Amount of exchangeable ions in $250 \mathrm{~mL}$ labeled solution $=0.750$ mmol 


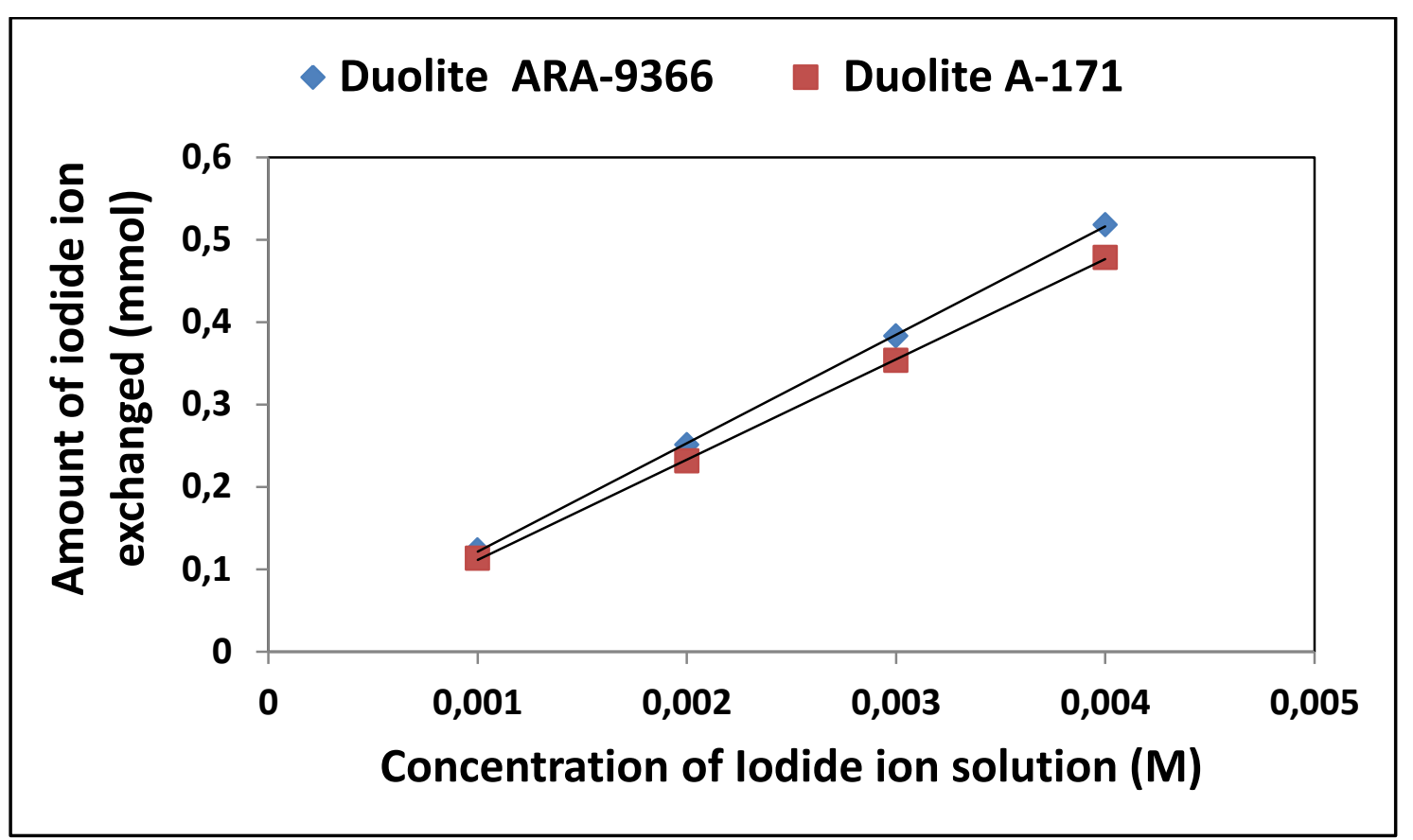

Figure 4. Correlation between concentration of iodide ion solution and amount of iodide ion exchanged.

Amount of ion exchange resin $=1.000 \mathrm{~g}$, Volume of labeled ionic solution $=250 \mathrm{~mL}$, Temperature $=40.0{ }^{\circ} \mathrm{C}$ Correlation coefficient (r) for Duolite ARA-9366 $=0.9999$,

Correlation coefficient (r) for Duolite A-171 $=0.9999$.

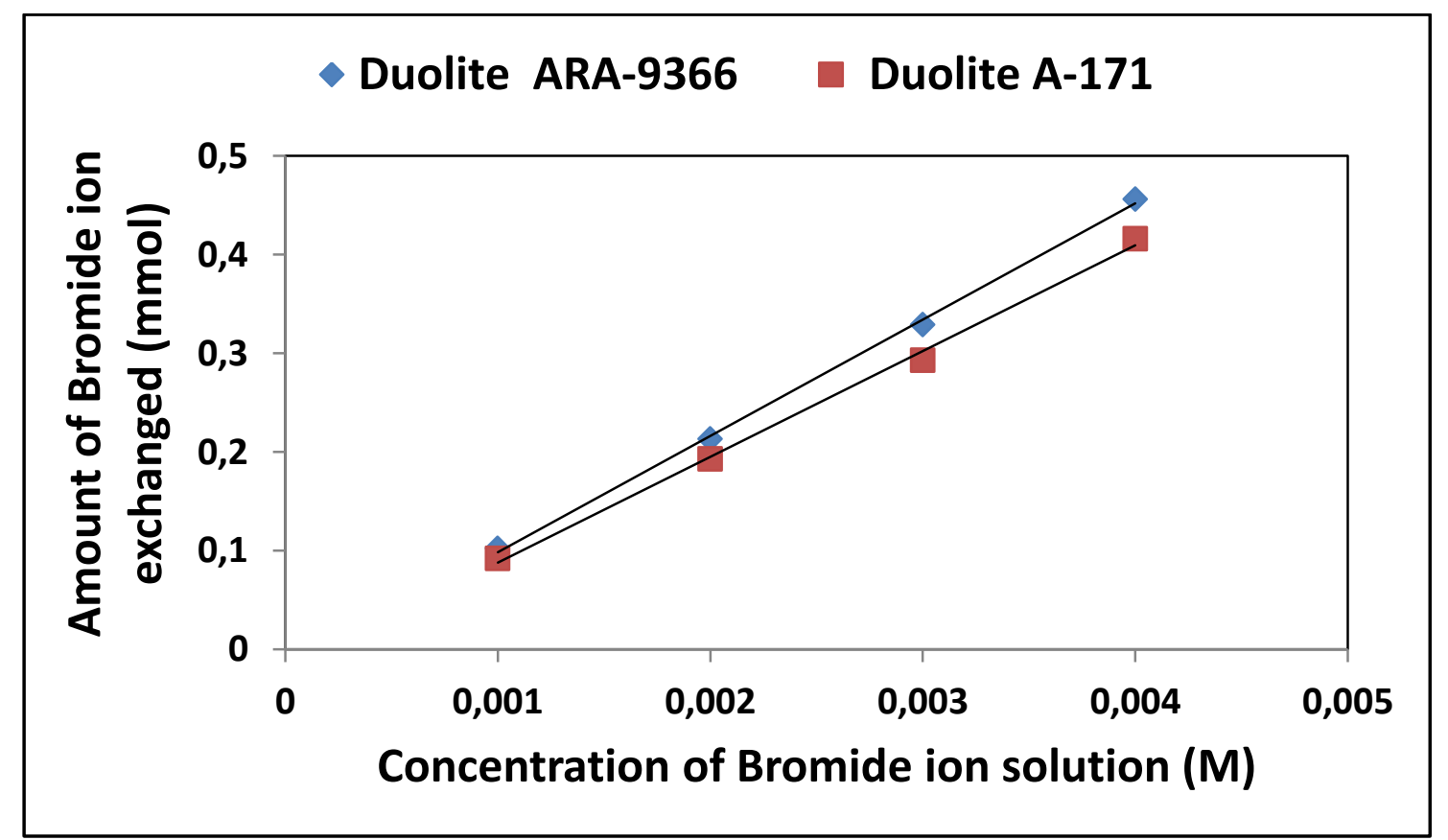

Figure 5. Correlation between concentration of bromide ion solution and amount of bromide ion exchanged.

Amount of ion exchange resin $=1.000 \mathrm{~g}$, Volume of labeled ionic solution $=250 \mathrm{~mL}$, Temperature $=40.0^{\circ} \mathrm{C}$, Correlation coefficient (r) for Duolite ARA-9366 $=0.9995$,

Correlation coefficient (r) for Duolite A-171 $=0.9987$ 


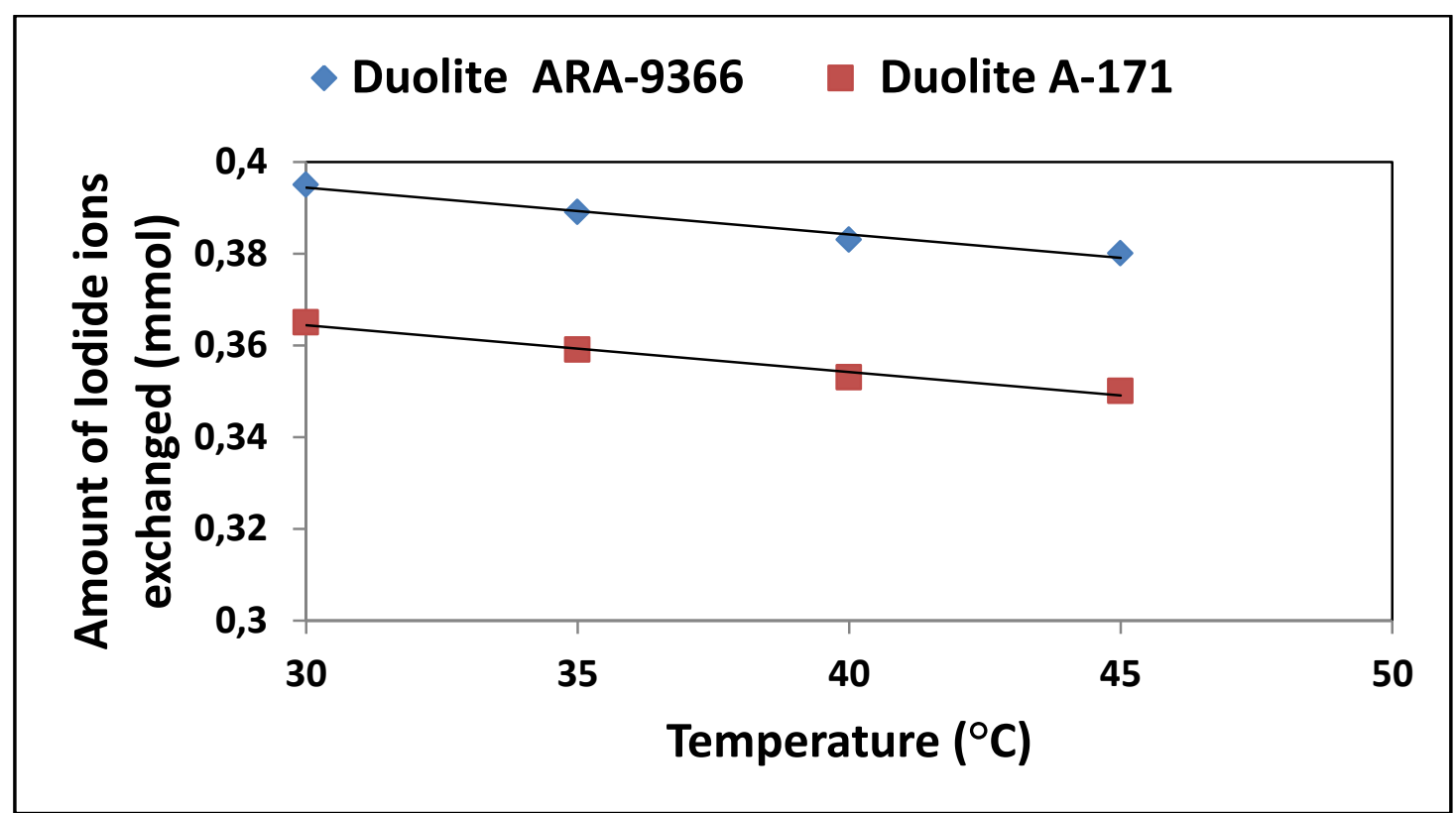

Figure 6. Correlation between Temperature of exchanging medium and amount of iodide ion exchanged.

Amount of ion exchange resin $=1.000 \mathrm{~g}$, Concentration of labeled exchangeable ionic solution $=0.003 \mathrm{M}$, Volume of labeled ionic solution $=250 \mathrm{~mL}$, Amount of exchangeable ions in $250 \mathrm{~mL}$ labeled solution $=0.750$ mmol, Correlation coefficient (r) for Duolite ARA-9366 $=-0.9898$

Correlation coefficient (r) for Duolite A-171 $=-0.9898$

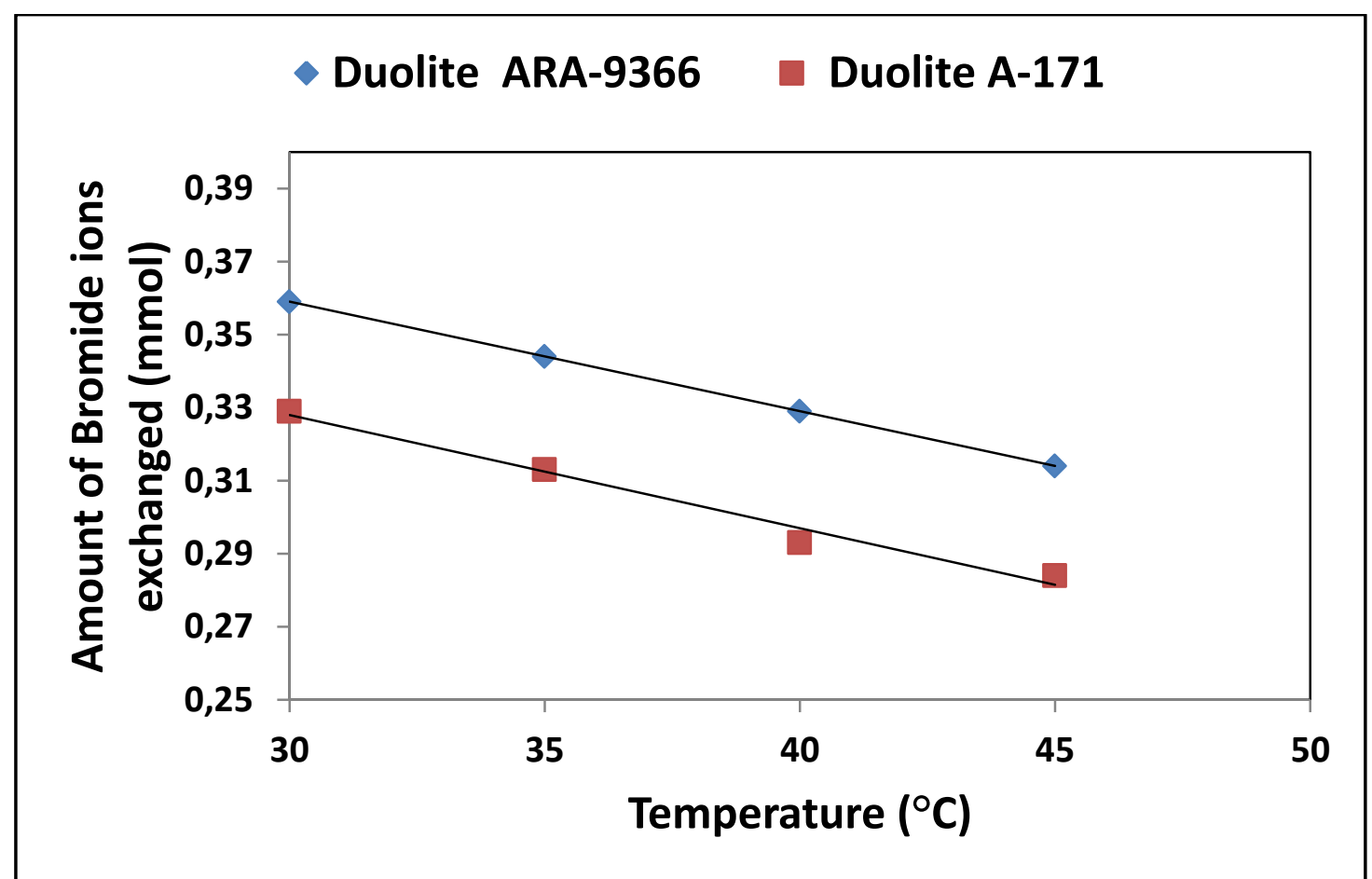

Figure 7. Correlation between Temperature of exchanging medium and amount of bromide ion exchanged.

Amount of ion exchange resin $=1.000 \mathrm{~g}$, Concentration of labeled exchangeable ionic solution $=0.003 \mathrm{M}$, Volume of labeled ionic solution $=250 \mathrm{~mL}$, Amount of exchangeable ions in $250 \mathrm{~mL}$ labeled solution $=0.750$ mmol, Correlation coefficient (r) for Duolite ARA-9366 $=-1.0000$, Correlation coefficient (r) for Duolite A-171 = -0.9904 


\section{RESULTS AND DISCUSSION}

\section{1. Comparative study of ion-isotopic exchange reactions}

In the present investigation it was observed that due to the rapid ion-isotopic exchange reaction taking place, the activity of solution decreases rapidly initially, then due to the slow exchange the activity of the solution decreases slowly and finally remains nearly constant. Preliminary studies show that the above exchange reactions are of first order [16-20]. Therefore logarithm of activity when plotted against time gives a composite curve in which the activity initially decreases sharply and thereafter very slowly giving nearly straight line (Figure 1), evidently rapid and slow ion-isotopic exchange reactions were occurring simultaneously [16-20]. Now the straight line was extrapolated back to zero time. The extrapolated portion represents the contribution of slow process to the total activity which now includes rapid process also. The activity due to slow process was subtracted from the total activity at various time intervals. The difference gives the activity due to rapid process only. From the activity exchanged due to rapid process at various time intervals, the specific reaction rates $(k)$ of rapid ion-isotopic exchange reaction were calculated. The amount of iodide / bromide ions exchanged ( $\mathrm{mmol}$ ) on the resin were obtained from the initial and final activity of solution and the amount of exchangeable ions in $250 \mathrm{~mL}$ of solution. From the amount of ions exchanged on the resin $(\mathrm{mmol})$ and the specific reaction rates $\left(\mathrm{min}^{-1}\right)$, the initial rate of ion exchanged $(\mathrm{mmol} / \mathrm{min})$ was calculated.

Because of larger solvated size of bromide ions as compared to that of iodide ions, it was observed that the exchange of bromide ions occurs at the slower rate than that of iodide ions. Hence under identical experimental conditions, the values of specific reaction rate $\left(\mathrm{min}^{-}\right.$ ${ }^{1}$ ), amount of ion exchanged ( $\left.\mathrm{mmol}\right)$ and initial rate of ion exchange $(\mathrm{mmol} / \mathrm{min})$ are calculated to be lower for bromide ion-isotopic exchange reaction than that for iodide ionisotopic exchange reaction as summarized in Tables 3 and 4. For both bromide and iodide ion-isotopic exchange reactions, under identical experimental conditions, while temperature remaining constant at $40.0{ }^{\circ} \mathrm{C}$, the values of specific reaction rate increases with increase in ionic concentration from $0.001 \mathrm{M}$ to $0.004 \mathrm{M}$ (Table 3). However, at constant ionic concentration of $0.003 \mathrm{M}$, the specific reaction rate was observed to decrease with rise in temperature from $30.0^{\circ} \mathrm{C}$ to $45.0^{\circ} \mathrm{C}$, (Table 4). Thus in case of Duolite ARA-9366 at $40.0^{\circ} \mathrm{C}$ when the ionic concentration increases from $0.001 \mathrm{M}$ to $0.004 \mathrm{M}$, the specific reaction rate values for iodide ion-isotopic exchange increases from 0.155 to $0.188 \mathrm{~min}^{-1}$, while for bromide ion-isotopic exchange the values increases from 0.128 to $0.146 \mathrm{~min}^{-1}$. Similarly in case of Duolite A-171, under identical experimental conditions, the values for iodide ionisotopic exchange increases from 0.115 to $0.156 \mathrm{~min}^{-1}$, while for bromide ion-isotopic exchange the values increases from 0.100 to $0.127 \mathrm{~min}^{-1}$. However when concentration of ionic solution is kept constant at $0.003 \mathrm{M}$ and temperature is raised from $30.0{ }^{\circ} \mathrm{C}$ to $45.0^{\circ} \mathrm{C}$, in case of Duolite ARA-9366 the specific reaction rate values for iodide ion-isotopic exchange decreases from 0.199 to $0.167 \mathrm{~min}^{-1}$, while for bromide ion-isotopic exchange the values decreases from 0.151 to $0.135 \mathrm{~min}^{-1}$. Similarly in case of Duolite A-171, under identical experimental conditions, the specific reaction rate values for iodide ion-isotopic exchange decreases from 0.166 to $0.133 \mathrm{~min}^{-1}$, while for bromide ion-isotopic exchange the values decreases from 0.132 to $0.111 \mathrm{~min}^{-1}$. From the results, it appears that iodide ions exchange at the faster rate as compared to that of bromide ions which was related to the extent of solvation (Tables 3 and 4). 
From the knowledge of $A_{i}, A_{f}$, volume of the exchangeable ionic solution $(V)$ and mass of ion exchange resin $(m)$, the $K_{d}$ value was calculated by the equation

$$
K_{d}=\left[\left(A_{i}-A_{f}\right) / A_{f}\right] \times V / m
$$

Previous studies [21,22] on halide ion distribution coefficient on strong and weak basic anion exchange resins indicate that the selectivity coefficient between halide ions increased at higher electrolyte concentrations. Adachi et al. [23] observed that the swelling pressure of the resin decreased at higher solute concentrations resulting in larger $K_{d}$ values. The temperature dependence of $\mathrm{K}_{\mathrm{d}}$ values on cation exchange resin was studied by Shuji et al. [24]; were they observed that the values of $\mathrm{K}_{\mathrm{d}}$ increased with fall in temperature. The present experimental results also indicates that the $K_{d}$ values for bromide and iodide ions increases with increase in ionic concentration of the external solution, however with rise in temperature the $K_{d}$ values were found to decrease. Thus in case of Duolite ARA-9366 at $40.0{ }^{\circ} \mathrm{C}$ when the ionic concentration increases from $0.001 \mathrm{M}$ to $0.004 \mathrm{M}$, the $\log \mathrm{K}_{\mathrm{d}}$ values for iodide ions increases from 6.7 to 8.2, while for bromide ions the values increases from 3.3 to 5.1. Similarly in case of Duolite A-171, under identical experimental conditions, the $\log \mathrm{K}_{\mathrm{d}}$ values for iodide ions increases from 6.0 to 7.5, while for bromide ions the values increases from 2.6 to 4.3 . However when concentration of ionic solution is kept constant at $0.003 \mathrm{M}$ and temperature is raised from $30.0{ }^{\circ} \mathrm{C}$ to $45.0{ }^{\circ} \mathrm{C}$, in case of Duolite ARA-9366 the $\log \mathrm{K}_{\mathrm{d}}$ values for iodide ions decreases from 9.0 to 7.3, while for bromide ions the values decreases from 5.8 to 4.1 . Similarly in case of Duolite A-171, under identical experimental conditions, the log $\mathrm{K}_{\mathrm{d}}$ values for iodide ions decreases from 8.4 to 6.6 , while for bromide ions the values decreases from 5.0 to 3.5. It was also observed that the $\mathrm{K}_{\mathrm{d}}$ values for iodide ion-isotopic exchange reaction were calculated to be higher than that for bromide ion-isotopic exchange reaction (Tables 3 and 4).

\section{2. Comparative study of anion exchange resins}

From the Table 3 and 4, it is observed that for iodide ion-isotopic exchange reaction by using Duolite ARA-9366 resin, the values of specific reaction rate $\left(\mathrm{min}^{-1}\right)$, amount of iodide ion exchanged ( $\mathrm{mmol})$, initial rate of iodide ion exchange $(\mathrm{mmol} / \mathrm{min})$ and $\log \mathrm{K}_{\mathrm{d}}$ were 0.176 , $0.383,0.067$ and 7.8 respectively, which was higher than $0.142,0.353,0.050$ and 7.0 respectively as that obtained by using Duolite A-171 resins under identical experimental conditions of $40.0^{\circ} \mathrm{C}, 1.000 \mathrm{~g}$ of ion exchange resins and $0.003 \mathrm{M}$ labeled iodide ion solution. The identical trend was observed for the two resins during bromide ion-isotopic exchange reactions.

From Table 3, it is observed that using Duolite ARA-9366 resins, at a constant temperature of $40.0{ }^{\circ} \mathrm{C}$, as the concentration of labeled iodide ion solution increases $0.001 \mathrm{M}$ to $0.004 \mathrm{M}$, the percentage of iodide ions exchanged increases from $49.20 \%$ to $51.80 \%$. While using Duolite A-171 resins under identical experimental conditions the percentage of iodide ions exchanged increases from $45.20 \%$ to $47.80 \%$. Similarly in case of bromide ion-isotopic exchange reaction, the percentage of bromide ions exchanged increases from $40.80 \%$ to $45.60 \%$ using Duolite ARA-9366 resin, while for Duolite A-171 resin it increases from 36.80 $\%$ to $41.60 \%$. The effect of ionic concentration on percentage of ions exchanged is graphically represented in Figure 2.

From Table 4, it is observed that using Duolite ARA-9366 resins, for $0.003 \mathrm{M}$ labeled iodide ion solution, as the temperature increases $30.0{ }^{\circ} \mathrm{C}$ to $45.0^{\circ} \mathrm{C}$, the percentage of iodide ions exchanged decreases from $52.70 \%$ to $50.60 \%$. While using Duolite A-171resins under 
identical experimental conditions the percentage of iodide ions exchanged decreases from $48.70 \%$ to $46.60 \%$. Similarly in case of bromide ion-isotopic exchange reaction, the percentage of bromide ions exchanged decreases from $47.90 \%$ to $41.80 \%$ using Duolite ARA-9366 resin, while for Duolite A-171 resin it decreases from $43.90 \%$ to $37.80 \%$. The effect of temperature on percentage of ions exchanged is graphically represented in Figure 3.

The overall results indicate that under identical experimental conditions, as compared to Duolite A-171 resins, Duolite ARA-9366 resins shows higher percentage of ions exchanged. Thus Duolite ARA-9366 resins show superior performance than Duolite A-171resins under identical operational parameters.

\section{3. Statistical Correlations}

The results of present investigation show a strong positive linear co-relationship between amount of ions exchanged and concentration of ionic solution (Figures 4,5). In case of iodide ion-isotopic exchange reaction, the value of correlation coefficient $(r)$ was calculated as 0.9999 for both Duolite ARA-9366 and Duolite A-171 resins, while for bromide ion-isotopic exchange reaction, the values of $r$ were calculated as 0.9995 and 0.9987 for the two resins respectively. There also exist a strong negative co-relationship between amount of ions exchanged and temperature of exchanging medium (Figures 6,7). In case of iodide ionisotopic exchange reactions the value of $r$ was calculated as -0.9898 for both the resins. Similarly in case of bromide ion-isotopic exchange reactions the $r$ values were calculated as 1.0000 and -0.9904 respectively for the two resins.

\section{CONCLUSION}

The experimental work carried out in the present investigation will help to standardize the operational process parameters so as to improve the performance of selected nuclear grade ion exchange resins. The radioactive tracer technique used here can also be applied for characterization of different nuclear as well as non-nuclear grade ion exchange resins.

\section{Acknowledgement}

The author is thankful to Professor Dr. R.S. Lokhande (Retired) for his valuable help and support by providing the required facilities so as to carry out the experimental work in Radiochemistry Laboratory, Department of Chemistry, University of Mumbai, Vidyanagari, Mumbai -58.

\section{References}

[1] Samanta S. K., Ramaswamy M., Misra B. M., Sep. Sci. Technol. 27 (1992) 255-267.

[2] Samanta S. K., Ramaswamy M., Sen P., Varadarajan N., Singh R. K., Removal of radiocesium from alkaline IL waste, Natl Symp. On Management of Radioactive and Toxic Wastes (SMART-93), Kalpakkam, 1993, Bhabha Atomic Research Centre, Bombay 1993, 56-58.

[3] Samanta S. K., Theyyunni T. K., Misra B. M., J. Nucl. Sci. Technol. 32 (1995) 425-429. 
[4] Kulkarni Y., Samanta S. K., Bakre S. Y., Raj K., Kumra M. S., Process for treatment of intermediate level radioactive waste based on radionuclide separation, Waste Management'96 (Proc. Int. Symp Tucson,AZ, 1996), Arizona Board of Regents, Phoenix, AZ (1996) (CD-ROM).

[5] Bray L. A., Elovich R. J., Carson K. J., Cesium Recovery using Savannah River Laboratory Resorcinol-formaldehyde Ion Exchange Resin, Rep. PNL- 7273, Pacific Northwest Lab., Richland, WA (1990).

[6] Singare P. U., Lokhande R. S., Madyal R. S., Open Journal of Physical Chemistry 1(2) (2011) 45-54.

[7] Singare P. U., Lokhande R. S., Madyal R. S., Rus. J. Gen. Chem. 80(3) (2010) 527-532.

[8] Tomoi M., Yamaguchi K., Ando R., Kantake Y., Aosaki Y., Kubota H., J. Appl. Poly. Sci. 64(6) (1997) 1161-1167.

[9] Zhu L., Liu Y., Chen J., Ind. Eng. Chem. Res. 48(7) (2009) 3261-3267.

[10] Kumaresan R., Sabharwal K. N., Srinivasan T. G., Vasudeva Rao P. R., Dhekane G., Solvent Extraction and Ion Exchange 24(4) (2006) 589-602.

[11] Cortina J. L., Warshawsky A., Kahana N., Kampel V., Sampaio C. H., Kautzman R. M., Reactive and Functional Polymers 54(1-3) (2003) 25-35.

[12] Sood D. D., Reddy A. V. R., Ramamoorthy N., Indian Association of Nuclear Chemists and Allied Scientists January (2004) 289-297.

[13] Clark M. W., Harrison J. J., Payne T. E., Journal of Colloid and Interface Science 356(2) (2011) 699-705.

[14] Dagadu C. P. K., Akaho E. H. K., Danso K. A., Stegowski Z., Furman L., Applied Radiation and Isotopes 70(1) (2012) 156-161.

[15] Koron N., Bratkic A., Ribeiro Guevara S., Vahcic M., Horvat M., Applied Radiation and Isotopes 70(1) (2012) 46-50.

[16] Singare P. U., Lokhande, R. S., Ionics 18(4) (2012) 351-357.

[17] Lokhande R. S., Singare P. U., Radiochim. Acta 95(03) (2007) 173-176.

[18] Lokhande R. S., Singare P. U., Patil V. V., Radiochemistry 50(06) (2008) 638-641.

[19] Lokhande R. S., Singare P. U., J. Porous Mater. 15(03) (2008) 253-258.

[20] Lokhande R. S., Singare P. U., Dole M. H., J. Nuclear and Radiochemical Sciences 7(02) (2006) 29-32.

[21] Heumann K. G., Baier, K., Chromatographia 15(11) (1982) 701-703.

[22] Singare P. U., Lokhande R. S., Patil V. V., Prabhavalkar T. S., Tiwari S. R. D., European J. Chemistry 1(1) (2010) 47-49.

[23] Adachi S., Mizuno T., Matsuno R., J. Chromatogr. A 708 (1995) 177-183.

[24] Shuji, A., Takcshi, M., Ryuichi, M., Biosci. Biotechnol. Biochem. 60(2) (1996) 338-340. 
[25] Pravin U. Singare, International Letters of Chemistry, Physics and Astronomy 6 (2013) $1-5$.

[26] P. U. Singare, International Letters of Chemistry, Physics and Astronomy 12 (2013) $1-13$.

[27] P. U. Singare, International Letters of Chemistry, Physics and Astronomy 12 (2013) 14-27.

( Received 24 August 2013; accepted 30 August 2013 ) 